${ }^{8}$ Erikson, H. A., Physic. Rev., 26, 629, 1925.

${ }^{9}$ Erikson, H. A., Ibid., 24, 502, 1924.

${ }^{10}$ Erikson, H. A., Ibid., 24, 622, 1924.

${ }^{11}$ Erikson, H. A., Ibid., 26, 465, 1925.

12 Loeb and Ashley, Proc. Nat. Acad. Sci., 10, 351, 1924.

${ }^{13}$ Blanc, A., J. Physique, 7, 825, 1908.

14 Loeb, L. B., Proc. Nat. Acad. Sci., 12, 35, 1926.

${ }^{15}$ Zahn, C. T., Physic. Rev., 24, 400, 1924.

${ }^{16}$ Franck, J., Jahrb. Rad. Elekt., 9, 252, 1912.

${ }^{17}$ Wellisch, E. M., Proc. Roy. Soc., A82, 500, 1909.

\title{
HIGH FREQUENCY RAYS OF COSMIC ORIGIN
}

\author{
By R. A. Millikan \\ Norman Bridge Laboratory, California Institute of Technolgoy
}

Read before the Academy November 9, 1925

It was as early as 1903 that the British physicists, McLennan and Burton $^{1}$ and Rutherford and Cooke ${ }^{2}$ noticed that the rate of leakage of an electric charge from an electroscope within an air-tight metal chamber could be reduced as much as $30 \%$ by enclosing the chamber within a completely encircling metal shield or box with walls several centimeters thick. This meant that the loss of charge of the enclosed electroscope was not due to imperfectly insulating supports, but must rather be due to some highly penetrating rays, like the gamma rays of radium, which could pass through metal walls as much as a centimeter thick and ionize the gas inside.

In view of this property of passing through relatively thick metal walls in measurable quantity, the radiation thus investigated was called the "penetrating radiation" of the atmosphere, and was at first quite naturally attributed to radioactive materials in the earth or air, and this is in fact the origin of the greater part of it. But in 1910 and 1911 it was found that it did not decrease as rapidly with altitude as it should upon this hypothesis. The first significant report upon this point was made by the Swiss physicist, Gockel, ${ }^{3}$ who took an enclosed electroscope up in a balloon with him to a height of 13,000 feet and reported that he found the "penetrating radiation" about as large at this altitude as at the earth's surface, and this despite the fact that according to Eve's" calculation it ought to have fallen to half its surface value in going up 250 feet.

In 1911, '12, '13 and '14 two physicists, Hess, ${ }^{6}$ a Swiss, and Kolhörster, ${ }^{6}$ a German, repeated these balloon-measurements of Gockel's, the latter going to a height of $9 \mathrm{~km}$., or 5.6 miles, and reported that they found this 
radiation decreasing a trifle for the first mile or so and then increasing until it reached a. value at $9 \mathrm{~km}$., according to Kolhörster's measurements, eight times as great as at the surface. This seemed to indicate that the penetrating rays came from outside the earth, and were, therefore, of some sort of cosmic origin. If so it was computed ${ }^{7}$ that in order to fit the Hess and Kolhörster data the rays had to have an absorption coefficient of 0.57 per meter of water and an ionizing power within a closed vessel sent to the top of our atmosphere of at least 500 ions per cc. per sec., in place of the 10 or 12 ions found in ordinary electroscopes at the surface. The war put a stop the world over to further studies of this sort; but as soon as we could get the proper instruments built after the war in the newly equipped Norman Bridge Laboratory of Physics, I. S. Bowen and myself went to Kelly Field, near San Antonio, Texas, with four little recording electroscopes which we succeeded in the spring of 1922 in sending up in sounding balloons to almost twice the heights which had previously been attained. The highest flight reached the altitude of $15.5 \mathrm{~km}$., or nearly 10 miles.

These instruments were interesting in that, though they were built of steel to hold $300 \mathrm{cc}$. of air at $150 \mathrm{lbs}$.' pressure, and were provided each with a recording barometer, thermometer and electroscope, also with two different sets of moving photographic films and the necessary driving mechanism, the total weight of the whole instrument was yet but 190 grams, or about 7 ounces. The altitudes were determined not only from the now well-established law of ascent of balloons, but also by direct, two theodolite observations which Major Wm. R. Blair of the U. S. Signal Corps kindly sent Lieutenant McNeil to Kelly Field for the express purpose of making for us.

In these experiments we expected, if the results previously reported were correct, to find very large rates of discharge; for our instruments went up to such heights that eighty-eight per cent of the atmosphere had been left beneath them, and only twelve per cent was left to cut down, by its absorption, the intensity of the hypothetical rays entering from outside. In other words, our electroscopes should have been exposed to radiations approaching in intensity those existing at the very top of our atmosphere. We actually failed to find anything like the computed rates of discharge. Our experiments were in agreement with those of the European observers in that our electroscopes showed a somewhat higher rate of discharge at high altitudes than at the surface, but at the same time they proved conclusively that a radiation of the assumed properties did not exist, our observed rates of discharge being not more than one-fourth the computed amounts.

Since the origin of the "penetrating rays" was still uncertain, Dr. Russell Otis and myself in the summer of 1923 went to the top of Pike's 
Peak for the sake of making absorption experiments upon these radiation at the highest altitude to which we could carry large quantities of absorbing materials. For if the rays were not of cosmic origin they did not need to be more penetrating than are the gamma rays from radioactive materials, while if they were of cosmic origin the sounding balloon experiments of Bowen and myself had shown that they must be very much harder (more penetrating) than anybody had thus far assumed. What was needed was absorption experiments to determine just what sort of rays they actually were.

We carried 300 pounds of lead and a $6^{\prime} \times 6^{\prime} \times 6^{\prime}$ tank of water to the top of the peak and obtained as the net result of these absorption experiments the definite proof that the rays found at the top of Pike's Peak were predominantly of the hardness of ordinary gamma rays, and further that they were very largely, if not entirely, of local origin, since local conditions, such as a heavy snow storm and blizzard, which occurred while we were there, varied their intensity nearly as much inside a screen of $4.8 \mathrm{~cm}$. of lead as outside. Kolhörster had by this time, after the brief publication of our Kelly Field data, and as a result, also, of new experiments made subsequently to them in crevasses and holes in glaciers in the Alps reduced his estimated absorption coefficients ${ }^{8}$ from 0.57 to 0.25 , a change he regards as within the limits of his experimental uncertainties, but a change which made the assumed rays so hard as to be no longer irreconcilable with our sounding balloon observations. But we found that our Pike's Peak observations were not yet compatible with his now (1923) assumed characteristics of rays of cosmic origin, viz., rays which produce 2 ions per sec. per cc. at the earth's surface, and have a coefficient of 0.25 per meter of water. For while in going from the altitude of Pasadena to that of Pike's Peak the number of ions observed with the unshielded electroscope increased from 11.6 to 22.2 , an increase of 10.6 ions, the number of ions observed through the shield of $4.8 \mathrm{~cm}$. of lead increased but from 9.37 to 11.6 , an increase of only 2.23 ions. But radiation of the characteristics assumed above would have caused by itself, inside our lead screen, an increase of 3:34 ions, even if none of the large increase in radiation shown by the unshielded observations got through the lead shield-a supposition which we believed to be contrary to fact. In a word, our Pike's Peak observations showed that if rays of cosmic origin existed at all they must be of different characteristics from any as yet suggested, and they further showed most interestingly that a very copious soft radiation of unknown origin existed at the altitude of Pike's Peak.

Accordingly, Mr. Harvey Cameron and myself planned some new experiments for the summer of 1925 which were designed.

(1) To settle definitely the question of the existence or non-existence of a small, very penetrating radiation of cosmic origin-a radiation so hard 
as to be uninfluenced by, and hence unobservable with the aid of, such screens as we had taken to Pike's Peak-and,

(2) To throw light on the cause of the variation with altitude of the radiation of gamma-ray hardness which our absorption experiments on Pike's Peak showed to be more than twice as copious there as at Pasadena.

The only possible absorbing material obtainable in the immense quantities needed, and of homogeneous and non-radioactive constitution, were the waters of very deep snow-fed lakes-snow-fed because the results of underwater experiments which we had previously carried on near Pasadena had been vitiated by our discovery that the waters were appreciably radioactive. We felt that there was much uncertainty as to how much this cause might have affected the European observations in and about glaciers. Further, our Pike's Peak experiments had demonstrated that if any of the penetrating rays were of cosmic origin the ionization due to them in our electroscope at sea level had to be much less than the 2 ions, assumed above, out of the 11.6 observed, the experimental error being, say, half an ion. No crucial tests could, therefore, possibly be made unless we could find very deep, non-radioactive lakes at very high altitudes where cosmic rays, if they existed, had two or three times the ionizing effect to be expected from them at sea level. We needed at least three ions due to cosmic rays, to vary with absorbing materials, if we were to obtain unambiguous evidence.

We chose for the first experiments Muir Lake (11,800 feet high), just under the brow of Mount Whitney, the highest peak in the United States, a beautiful snow-fed lake hundreds of feet deep and some 2000 feet in diameter. Here we worked for the last ten days in August, sinking our electroscopes to various depths down to 67 feet. Our experiments brought to light altogether unambiguously a radiation of such extraordinary penetrating power that the electroscope-readings kept decreasing down to a depth of 50 feet below the surface. The atmosphere above the lake was equivalent in absorbing power to 23 feet of water, so that here were rays so penetrating that, if they came from outside the atmosphere, they had the power of passing through $50+23=73$ feet of water, or the equivalent of 6 feet of lead, before being completely absorbed. The most penetrating $\mathrm{X}$-rays that we produce in our hospitals cannot go through half an inch of lead. Here were rays at least a hundred times more penetrating than these, and having an absorption coefficient but one twenty-fifth, instead of "about one-tenth of that of the hardest known gamma rays."8

How unambiguous was the experimental evidence may be seen from the fact that with the aid of a new electroscope of high sensitivity the change in ions per cc. per sec. in going from the surface of Muir Lake to the depth of 15 meters (50 feet) was from 13.9 ions to 3.8 ions, or a decrease to about a fourth value. The largest decrease below a surface 
reading reported by Kolhörster due to sinking electroscopes in water ${ }^{8}$ was 2.1 ions, or a decrease of perhaps $20 \%$, so that we have here obtained an altogether new precision of measurement and unambiguity of evidence.

To obtain definite evidence as to whether these very hard rays were of cosmic origin, coming in wholly from above and using the atmosphere merely as an absorbing blanket, we next went to another very deep snowfed lake, Lake Arrowhead in the San Bernardino mountains, 300 miles farther south and 6700 feet lower in altitude, where the Arrowhead Development Company kindly put all their facilities at our disposal. The atmosphere between the two altitudes has an absorbing power equivalent to about 6 feet of water. Within the limits of observational error, every reading in Arrowhead Lake corresponded to a reading 6 feet farther down in Muir Lake, thus showing that the rays do come in definitely from above, and that their origin is entirely outside the layer of atmosphere between the levels of the two lakes.

Analysis of our absorption curves shows that the rays are not homogeneous but are hardened as they go through the atmosphere, just as Xrays are hardened by being filtered through a lead screen. Our hardest observed rays have an absorption coefficient of 0.18 per meter of water and the softest which get down to Muir Lake a coefficient of 0.3 per meter. The sounding balloon experiments of Bowen and myself make it improbable that they become very much softer than this at the top of the atmosphere, since otherwise we should have obtained larger readings in our very high flight.

Observations carried on day and night for four consecutive days on Pike's Peak at an altitude of 14,100 feet, and for two consecutive days on Mount Whitney at an altitude of 13,500 feet reveal no preferential direction in the heavens from which the rays come. Within the limits of our uncertainty of measurement, then, these rays shoot through space equally in all directions.

When absorption coefficients are reduced to wave length by a formula ${ }^{9}$ of probable, though not yet of certain, validity our hardest observed rays have the wave-length $0.00038 \AA$, and those of longer wave-length go up to nearly twice this value, i.e., we find a spectrum about an octave in width in a frequency region about 2000 times higher than that of the mean $X$-ray ( $1 \AA$ ), or as far above $X$-rays as $X$-rays are above light. The shortest wavelength just computed corresponds to a frequency 10,000,000 times higher than that of visible light.

When these extraordinarily high frequency rays strike the earth, according to the now well-established Compton effect, they should be transformed partially into soft rays of just about the hardness of the soft rays which we have actually observed on Pike's Peak and Mount Whitney. The reason these soft rays were more plentiful on the mountain peaks than at Pasadena 
would then be found simply in the fact that there are about three times as many of the hard rays to be transformed at the altitudes of the peaks as at that of Pasadena. This seems to be the solution of the second of our summer's problems.

We can draw some fairly reliable conclusions of a general sort as to the origin of these very penetrating and very high frequency rays. The most penetrating rays that we have known anything about thus far, the gamma rays of radium and thorium, are produced only by nuclear transformations within atoms. In other words, they are produced by the change of one atom over into another atom, or by the creation of a new type of atom. It is scarcely possible, then, to avoid the conclusion that these still more penetrating rays which we have here been studying are produced similarly by nuclear transformations of some sort. But these transformations must be enormously more energetic than are those taking place in any radioactive changes that we know anything about. For, according to our present knowledge, the frequency of any emitted ray is proportional to the energy of the subatomic change giving birth to it. We can scarcely avoid the conclusion, then, that nuclear changes having an energy value perhaps fifty times as great as the energy changes involved in observed radioactive processes are taking place all through space, and that signals of these changes are being sent to us in these high frequency rays.

The energy of the nuclear change that corresponds to the formation of helium out of hydrogen is known, and from it we have computed the corresponding frequency and found it to correspond closely to the highest frequency rays which we have observed this summer. The computed frequencies of these cosmic rays also correspond closely to the energy involved in the simple capture of an electron by a positive nucleus. Thus, the highest speed $\beta$-ray emitted by thorium leaves its mother atom with a speed which is equivalent to the energy acquired by the fall of an electron through $7,540,000^{10}$ volts. This electron in order to get out of the mother atom was obliged to move against the pull upon it of the positive nucleus, and in this act it gained a potential energy the equivalent of a fall through 4,400,000 volts. ${ }^{11}$ If this same electron had reversed its path and plunged into the nucleus it should have generated in so doing a $12,000,000$ volt ray $(7,540$,$000+4,400,000)$. The cosmic rays with which we have been dealing have frequencies which make them the equivalent of from 12 to 30 million-volt rays. It is not improbable that the capture of an electron by the nucleus of a light atom involves a higher energy than its capture by a heavy one, so that such captures as are here discussed constitute, perhaps, the most plausible hypothesis as to the origin of these rays.

Is it possible to imagine such a phenomenon going on all through space? The difficulty is not so insuperable, in view of the transparency even of large amounts of matter for these hard rays combined with Hubbell's 
recent proof ${ }^{12}$ at the Mount Wilson Observatory that some of the spiral nebulae are at least a million light years away. The centers at which these nuclear changes are taking place would then only have to occur at extraordinarily widely scattered intervals to produce the intensity of the radiation observed at Muir Lake.

The only alternative hypothesis to that above presented of high frequency rays traversing space in all directions, might seem to be to assume that the observed rays are generated in the upper layers of the atmosphere by electrons shooting through space in all directions with practically the speed of light. This hypothesis might help some in interpreting the mysterious fact of the maintenance of the earth's negative charge, but it meets with insuperable obstacles, I think, in explaining quantitatively the variation with altitude of the ionization in closed vessels. In any case, in its most important aspect, this hypothesis is very much like the one presented above, for it, too, fills space with rays of one sort or another traveling in all directions with the speed of light. From some such conception as this there now seems to be no escape. And yet it is a conception which is almost too powerful a stimulus to the imagination. Professor MacMillan of Chicago will wish to see in it evidence for the condensation into matter out somewhere in space of the light and heat continually being radiated into space by the sun and stars, ${ }^{13}$ an altogether permissible speculation. Unfortunately the psychics will of course be explaining all kinds of telepathies with the aid of these cosmic rays. But, be that as it may, the simple experimental facts, as shown by the foregoing work, are:

(1) That these extraordinary penetrating rays exist;

(2) That their mass absorption coefficient may be as high as 0.18 per meter of water;

(3) That they are not homogeneous, but are distributed through a spectral region far up above X-ray frequencies-probably 1000 times the mean frequencies of $\mathrm{X}$-rays;

(4) That these hard rays stimulate, upon striking matter, softer rays of about the hardness predicted by the theory of the Compton effect;

(5) That these rays come into the earth with equal intensity day and night and at all hours of the day or night, and with practically the same intensity in all directions.

Mr. I. S. Bowen, Dr. Russell Otis, Mr. G. Harvey Cameron and myself, all of whom have participated in this investigation and have received invaluable aid from the instrument maker, Mr. Julius Pearson, will publish full details of this work elsewhere.

\footnotetext{
${ }^{1}$ McLennan and Burton, Physic. Rev., 16, 184, 1903.

2 Rutherford and Cooke, Ibid., 16, 183, 1903.

${ }^{3}$ Gockel, Physik Zeit., 11, 280, 1910.

${ }^{4}$ Eve, Phil. Mag., 21, 26, 1911.
} 
5 Hess, Physik Zeit., 12, 998, 1911, and 13, 1084, 1912.

6 Kolhörster, Ibid., 14, 1153, 1913, and D. Physik Ges., July 30, 1914.

7 E. v. Schweidler, Elster u.Geitel Fest schrift, p. 415, 1915.

${ }^{8}$ Kolhörster, Sitz.-Ber. Preuss. Akad. Wiss, 34, 366, 23.

${ }^{9}$ N. Ahmad, Proc. Roy. Soc., A109, 206, 1925.

${ }^{10}$ Report of Committee on X-Rays and Radioactivity of National Research Council, 1925 , p. 92.

${ }^{11}$ Report of Committee on X-Rays and Radioactivity of National Research Council, 1925 , p. 68.

12 Hubbell, Pop. Astron., 33, pp. 252-255, 1925.

${ }^{13}$ MacMillan, Science, 62, 122, 1925.

\title{
THE JOULE-THOMSON EFFECT IN AIR ${ }^{1}$
}

\section{By J. R. ROEBUCK}

\author{
Department of Physics, University of Wisconsin
}

\section{Read before the Academy November 10, 1925}

Air compressed to a chosen pressure, lying between 30 and 220 atm., was passed through a temperature equalizing coil of pipe in an oil bath held at one of a series of temperatures between $25^{\circ}$ and $300^{\circ} \mathrm{C}$., around a resistance thermometer bulb, through the wall of a round ended tube of porous procelain, around a second thermometer inside the porcelain tube, through a control valve where it dropped to atmospheric pressure and finally back to the compressor. The oil-bath temperature was held constant by means of electrical heating controlled by an electrical thermostat. The inlet pressure was held exceedingly constant by a rotating piston barostat which controlled a spill valve through which a small fraction of the compressed air could be wasted. The steadiness of the inlet pressure is vital to such work and a large amount of experimental attention was spent toward attaining it. The temperature of the inlet thermometer and the difference of temperature between the two thermometers was read on a Callendar-Griffiths bridge. The flow of air was measured roughly by a Venturi meter.

The performance of thís form of porous plug was studied in detail, particularly as depending on the external and internal arrangements. Theory demands that the difference of temperature across the wall should depend only on the temperature and pressure conditions, and not at all on the rate of flow or particular plug. All the data reported satisfied these conditions, except at the low pressure (large volume) state where kinetic energy effects were very difficult to control.

To obtain the maximum amount of information, the measurements were arranged in groups, in which the pressure dropped from the same initial 